\title{
O Serviço Social nas ONGs no campo da saúde: projetos societários em disputa*
}

\section{ONGs' Social Services in the field of health: collective projects in debate}

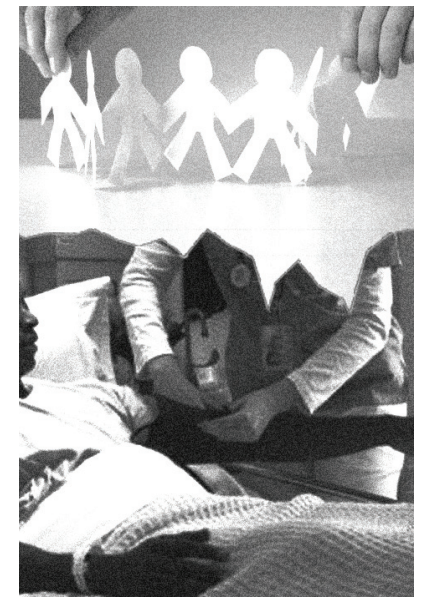

Graziela Scheffer Machado**

Resumo: O artigo faz uma análise do trabalho do Serviço Social nas organizações não governamentais (ONGs), no campo da saúde. O estudo visa identificar os dilemas e desafios no cotidiano das intervenções dos assistentes sociais nas sequelas da questão social. Também apresenta a pesquisa enquanto estratégia na construção de propostas coletivas na direção da cidadania, em contraponto à lógica do favor.

Palavras-chave: Organizações não Governamentais. Serviço Social. Saúde.

\begin{abstract}
The article analyses the Social Services' practices in the non-governmental organizations (ONGs) in the field of health. The study aims at identifying the dilemmas and challenges in the social workers' daily interventions in the sequels of the social issue. It also presents the research as a strategy in the construction of collective proposals towards citizenship, as a counterpoint to the logic of favour.
\end{abstract}

Keywords: Non-governmental organizations. Social Services. Health.

* Dedico este artigo às “minhas" estagiárias Paula Alexandra Trovisco (PUC-RJ) e a Nathália Marinho (UVA) por seu empenho na pesquisa e por sua contribuição no horizonte ético-político no trabalho cotidiano da ONG. Também à amiga Juliana Fiúza, pelas trocas teóricas, e a Sílvia Ladeira por suas críticas e revisão do artigo.

** Mestre em Serviço Social pela ESS-UFRJ, especialista em Saúde Mental Coletiva pela Escola de Saúde Pública do Rio Grande do Sul, professora da Pós-Graduação de Responsabilidade Social Organizacional da Universidade Veiga Almeida — Rio de Janeiro/RJ, Brasil, e assistente social do Programa Nacional de Proteção aos Defensores de Direitos Humanos no Ro de Janeiro (Iser).E-mail: grazi.email@ibest.com.br. 


\section{Pressupostos iniciais}

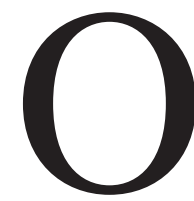

estudo partiu da experiência de trabalho do Serviço Social numa Organização não Governamental no campo da saúde. Temos como pressuposto que as ONGs não são monolíticas, ou seja, existe uma pluralidade de ações e discursos, e que muitas vezes aparecem entrelaçados na lógica do favor e da cidadania: diretos sociais, mobilização social, atendimento às necessidades sociais, o favor, moralização e humanização. Outro ponto é que o espaço institucional das ONGs é lugar de contradições e disputas por projetos societários, ou seja, se de um lado existem as pressões das lógicas mercantilista e privatista no trato da questão, de outro existem pressões relacionadas a discursos e ações ligadas à cidadania e aos direitos sociais, projetos profissionais e sujeitos atendidos, que trazem consigo suas reivindicações de acesso a um nível de civilidade mínimo (trabalho, moradia, alimentação, educação), da qual grande parte encontra-se à margem.

O Serviço Social no campo do "terceiro setor" vive um paradoxo, no sentido de reconhecermos o espaço das ONGS e a filantropia empresarial como estratégias de esvaziamento de direitos sociais, ao mesmo tempo que o assistente social enquanto um trabalhador assalariado não tem condições de recusar sua inserção nesse campo sócio-ocupacional, pois depende da venda de sua força de trabalho. O trabalho do Serviço Social possui na raiz profissional os dilemas da alienação e das determinações sociais que afetam a coletividade dos trabalhadores. O exercício profissional supõe a mediação do mercado de trabalho, por tratar-se de uma atividade assalariada (Iamamoto, 2008). Não há como negar o que a realidade nos impõe enquanto trabalhador assalariado; de modo que é necessário estarmos atentos aos inúmeros assistentes sociais e estagiários inseridos nas ONGs, que precisam de maior proximidade com o debate acadêmico, com a análise da realidade do cotidiano institucional, pois "a questão social se enfrenta com teoria e não com trabalho voluntário" (Vasconcelos, 2008). É essencial lembrar que as ONGs atualmente representam 5\% do PIB no brasileiro (Silva, 2009).

Então, ficam o desafio e o dilema atual de descobrirmos mecanismos e estratégias de assegurar os direitos sociais e de repolitizar a questão social nesses espaços sócio-ocupacionais, para além de contornos neoliberais. 
$\mathrm{O}$ artigo está organizado em três partes: a primeira tem como fio condutor o entendimento das metamorfoses históricas das ONGs no Brasil e suas implicações alicerçadas no capitalismo e no Estado. A segunda enfatiza as particularidades das ONGs no campo da saúde e o trabalho dos assistentes sociais. Na terceira, abordamos a pesquisa, enquanto dispositivo estratégico na construção de propostas democráticas que fortaleçam a cidadania.

\section{A trajetória histórica das ONGS no Brasil: de coadjuvante a ator principal}

“[...] Até bem pouco tempo atrás

Poderíamos mudar o mundo Quem roubou nossa coragem?"

(Renato Russo)

Para Alvarez et al. (2000), a sociedade civil constituiu-se amiúde em uma esfera disponível ou a mais importante para organizar a contestação política e cultural. Entretanto, a sociedade civil não é uma família ou uma aldeia global homogênea, mas um território de luta, minado muitas vezes por relações de poder não democráticas e pelos problemas constantes de racismo, heterossexismo, destruição ambiental e outras formas de exclusão. Atualmente estamos vivendo uma crescente predominância das ONGs nos movimentos latino-americanos. As ONGs por vezes agem como organizações "neo" ou "para", em vez de não governamentais, caminhando no sentido de ajudar a sustentar um setor público esvaziado pelo Estado e, ao mesmo tempo, tornar possível que este se exima do que era considerada sua responsabilidade.

O debate da articulação entre o Estado e a sociedade civil está intimamente relacionado ao processo constitutivo do voluntariado e à solidariedade, pois existe uma estreita vinculação entre a ação voluntária e a solidariedade e a sociedade civil, representada pelo "terceiro setor". Há uma tendência de constituir uma analogia entre terceiro setor e sociedade civil, passando esta última a ser denominada de conjunto de organizações, transpondo para o segundo plano o aspecto político, num processo de despolitização das desigualdades sociais (Fagundes, 2006).

As políticas sociais públicas são uma das respostas privilegiadas à questão social, ao lado de outras formas, acionadas para enfrentamento por distintos segmentos da 
sociedade civil, que possuem programas de atenção à pobreza, como corporações empresárias, organizações não governamentais, além de outras, de organização das classes subalternas, para fazer frente aos níveis crescentes de exclusão social a que se encontram submetidas (Iamamoto, 2004, p. 58). Conforme Fagundes (2006),

contextualizar as políticas sociais e o desenvolvimento do voluntariado e da solidariedade na atual sociedade constitui uma importante reflexão sobre compromisso efetivo das políticas sociais. O cenário é contraditório e paradoxal, ao mesmo tempo que se precisa de uma perspectiva que valorize a sociedade civil, tornando-a protagonista. Ela também precisa ser politizada, transpondo os interesses particulares e reducionistas, aproximando-a dos interesses mais gerais. A dimensão política da sociedade civil precisa ser construída; é desta maneira que ela vai se vincular ao espaço público democrático, constituindo-se como espaço de disputa, como uma posição efetiva de emancipação e de construção de estratégias para se opor à dominação representada pelo grande capital.

Montaño (2002) aponta que as ONGs nos anos 1970 e 1980 tinham um claro papel de articuladoras ao lado dos movimentos sociais e captadoras de recursos para estes. Ou seja, as ONGs surgiram com a missão de contribuir para a melhoria da organização interna, a articulação e a transferência de recursos captados de organismos internacionais para os movimentos sociais. Contudo, paulatinamente as ONGs começaram a ocupar o lugar dos movimentos sociais nos anos 1990. O autor ressalta que atualmente as ONGs tornaram-se o ator principal na negociação com o Estado, o que acarretou enfraquecimento dos movimentos sociais, deslocando a lógica das lutas e das reivindicações para o caminho da parceria e da negociação.

Em que pese tal afirmação, é necessário considerar que existe uma trama de aspectos complexos que ocasionaram a transformação ou o "enfraquecimento" dos movimentos sociais, que não são lineares.

Gonh (2000), na análise dos movimentos sociais no período de transição dos anos 1980 para os 1990, aponta diferentes aspectos que impulsionaram as seguintes mudanças:

1. A diminuição dos empregos na economia formal com o advento da reestruturação produtiva, o que acarretou instabilidades e incertezas, exigindo longas jornadas de trabalho, fato que interfere no tempo disponível das pessoas para participarem de mobilizações. As políticas econômicas dão suporte às atividades informais, que contribuem para a diminuição de trabalhadores filiados aos sindicatos. 
2. Ao longo dos anos 1980, com a transição democrática, o Estado tinha interesse em dialogar com os movimentos sociais, pois estava redemocratizando-se, sendo necessário mudar a imagem ligada à repressão e ao autoritarismo. Entretanto, nos anos 1990 o Estado prescinde do apoio dos movimentos para se legitimar diante da sociedade como agente não repressor.

3. Os movimentos populares progressistas perderam nos anos 1990 o apoio irrestrito que tiveram da Igreja Católica no período 1970-80, em sua ala da Teologia da Libertação.

4. As utopias sociais transformadoras, motores de mobilização e motivação das ações sociais coletivas, estiveram ausentes nesse fim de século, devido à influência da queda do muros de Berlim e dos regimes que sustentaram algumas delas.

5. Nos anos 1980, a participação social era pauta na agenda política das elites devido à crise de governabilidade das estruturas de poder do Estado autoritário, à legitimidade das demandas expressas pelos movimentos sociais e à conquista de espaços institucionais como interlocutores válidos. Nos anos 1990, a agenda política das elites dirigentes modifica-se em função de problemas internos e de novas políticas sociais impostas ao mundo capitalista, sendo que as arenas de negociação passaram a ser formadas pelo poder público. Orientadas em mecanismos jurisdicionais de controle, as elites políticas fomentaram o surgimento de movimentos sociais a seu favor.

6. Nos anos 1990 surgem novos movimentos sociais que têm foco nas questões éticas e na revalorização da vida humana, enfatizando questões de direitos no plano da identidade ou igualdade. Esses novos movimentos enfatizam a consciência individual em vez da coletiva, ancorada em valores de solidariedade humana; suas ações são organizadas em forma de "campanhas". Surgiram nos anos 1990 organizações de cunho misto de movimento social e ONG.

Em nosso ponto de vista, existem quatro fatores fundamentais para que as ONGs assumam o "papel" de principal agente de interlocução junto às políticas sociais, quais sejam: as transformações no mundo do trabalho com redução do trabalho vivo, impactando diretamente na fragilização da sindicalização e organização dos trabalhadores; ${ }^{1}$ o Estado sob hegemonia do capital financeiro estimulou

1. Segundo Faleiros (1986), os neoliberais em momentos de crise propõem a extinção das medidas sociais e a volta ao mercado de trabalho sem proteção estatal, e isto ocorre justamente num momento em que os trabalhadores estão mais vulneráveis pela desmobilização decorrente do desemprego e da procura de emprego. 
a criação de dispositivos legais de financiamento do atendimento de demandas sociais fora da esfera pública; o processo de democratização do país levou a maior complexidade e pulverização dos interesses dos sujeitos sociais; e, finalmente, a redução do financiamento internacional das ONGs no Brasil.

Desta forma, podemos apontar que o financiamento das ONGs pelo Estado foi uma via de mão dupla. Por um lado houve reconhecimento histórico da capacidade técnica e assistencial das ONGs vinculadas à questão social e à cidadania; por outro, possibilitou ao Estado a redução do custo das políticas sociais sem perder a legitimidade, já que ressaltou vetores consensuais dos direitos civis e políticos na manutenção da cidadania.

O Estado, por intermédio das ONGs, pôde construir uma nova concepção de cidadania social, fora da órbita da política pública estatal. Conforme Becker (2003, p. 117),

O Estado começa a reconhecer que as ONGs acumularam um capital de recursos, experiências e conhecimentos sobre as formas inovadoras de enfrentamento das questões sociais, que as qualificam como interlocutores e parceiros governamentais. Com isso, novas formas de articulação entre o Estado e a sociedade vêm sendo criadas, permitindo uma maior participação das ONGs na definição das políticas públicas.

Para Iamamoto (2001), o enfrentamento da questão social tem sido tensionado por distintos projetos societários na definição da estruturação e implantação das políticas públicas, que convivem em lutas no seu interior. A autora enfatiza três projetos em disputa:

a) O projeto de caráter universal e democrático, orientado pela Constituição de 1988, fundado nos princípios da participação social e controle social.

b) O projeto de inspiração neoliberal, que visa subordinar os direitos sociais à lógica do orçamento, alegando "crise fiscal", subvertendo o preceito constitucional à disponibilidade dos recursos.

c) "O projeto vinculado ao "terceiro setor", ${ }_{2}^{2}$ um desdobramento da proposta neoliberal, que expressa uma dupla via: transferência de responsabilidade gover-

2. O marco legal do terceiro setor engloba sob um mesmo título as instituições filantrópicas, o voluntariado e as organizações não governamentais, que contemplam desde aquelas mais combativas, oriundas de movimentos sociais, até filantropia empresarial (Iamamoto, 2008). Diante desse o cenário "nebuloso" do terceiro setor, pudemos constatar que a literatura profissional aponta como denominador comum na análise 
namental para ONGs e mercantilização do atendimento às necessidades sociais, evidente no campo da saúde, da educação, entre muitos outros.

Para Yazbek (2001), atualmente vivemos um movimento de refilantropização, que visa à substituição da lógica da cidadania, tendo como base o não reconhecimento dos direitos sociais historicamente conquistados, pois está alicerçada num discurso humanitário da solidariedade e da filantropia, alavancado por uma moralidade de ajuda aos necessitados. É preciso frisar ainda que esta perspectiva fortalece a lógica do favor em detrimento do direito. No Brasil, o favor perpassou o conjunto da existência nacional nas relações entre homens livres, sendo que o favor foi nossa principal mediação nas relações sociais (Schwarz, 1991, apud Iamamoto, 2008).

Contudo, é preciso salientar que a chamada refilantropização é acompanhada por um aprofundamento da racionalização e mercantilização do próprio trato da questão social. As empresas que financiam as ONGs exigem resultados de seus investimentos (relatórios, pesquisas de impactos etc.), que posteriormente possam ser utilizados para marketing social, vinculando imagens e discursos na órbita da questão social para venda de suas mercadorias. Acreditamos que o elemento novo da "filantropização" no momento atual é o aprofundamento da transformação da racionalidade do caráter humanitário em mercadorias.

Vivemos uma tensão entre a defesa de direitos sociais e a mercantilização dos atendimentos sociais (Iamamoto, 2001). Em relação à tendência da refilantropização mercantilizada, não podemos perder de vista a legislação social. Segundo Silva (2009), a Lei Orgânica da Assistência Social de 1993 e toda a legislação criada posterior a ela, que regula a relação das ONGs, implantam a concepção de assistência social como direito. Assim, usuários são vistos enquanto cidadãos, que requerem do estabelecimento outro tipo de relação além do favor, da caridade e do assistencialismo. As ONGs precisam adequar-se ao novo marco regulatório. "A legislação social é em boa parte responsável por essa mudança cultural da assistência social" (Silva, 2009, p. 54).

A partir desse contexto, observa-se que as ONGs não são a sociedade civil. Na verdade, são expressões condensadas de relações sociais, econômicas, políticas e culturais circunscritas historicamente e que hoje aparecerem hegemonicamente

\footnotetext{
uma crítica de sua imprecisão conceitual e despolitizada, pois tenta reduzir a sociedade civil a entidades sem fins lucrativos, tratadas como locus esvaziados de conflitos e tensões de classes, pautados em discursos de solidariedade, coesão social com um forte apelo moral ao bem comum.
} 
enquanto canais (sedimentados da lógica neoliberal) por onde a sociedade civil, principalmente a massa pauperizada, está sendo atendida. Em suma, as ONGs, como parte da sociedade civil que nos leva a considerar que também são arenas de lutas e disputas de projetos societários.

1.1 Um museu de grandes novidades: as ONGs no campo da saúde

[...] Eu vejo o futuro repetir o passado Eu vejo um museu de grandes novidades O tempo não para $[\ldots]$

(Cazuza)

É fundamental inicialmente observar que as ONGs no campo da saúde expressam uma nova construção social, que tem implicações nas políticas sociais e no fazer profissional. O novo se cria por meio do passado, transformando e recriando em novas formas nos processos sociais do presente (Iamamoto, 2008). Neste sentido, buscamos identificar quais são os traços do passado que se reatualizam no presente do trabalho do assistente social, nesse espaço sócio-ocupacional.

As ONGs no campo da saúde estiveram integradas aos movimentos de lutas sociais (como dos hansenianos, dos portadores de HIV-Aids e dos portadores de transtorno mental), sendo que as ONGs na saúde se constituíram historicamente enquanto um dispositivo de novas práticas e de experimentação para propostas alternativas aos modos predominantes de tratamento. A atuação das ONGs no campo da saúde concentrava-se predominantemente em uma vertente assistencialista, estendendo cuidados em saúde a grupos excluídos do atendimento do Estado ou de órgãos públicos. Com a criação do Sistema Único de Saúde (SUS), esta atuação perde parte de sua força, pois se estende o direito à saúde a todo cidadão. Ainda assim, persistem diversos espaços de intervenção (Becker, 2003).

Acreditamos que atualmente existem três diferentes perfis de ONGs no campo da saúde:

a) Perfil centrado na situação de saúde: neste segmento estão aglutinadas demandas de sujeitos com doenças "raras", na maioria das vezes crônicas, com alto 
custo para aquisição de medicamentos, sendo uma das principais características a luta social pelo acesso a medicamentos. Além disso, outra questão trazida por esses sujeitos é o enfrentamento do estigma, a vivência da discriminação perpetrada pela sociedade. O trabalho voluntário será composto e mobilizado a partir da experiência ou da proximidade com o processo de saúde-doença, focando o direito à vida e ao exercício da cidadania. Exemplos desse perfil são organizações de familiares e portadores de diferentes doenças, como: HIV-Aids, transtorno mental, fibrose cística, ostomizados etc. Acreditamos que estes segmentos são os mais atuantes nas arenas das lutas políticas junto ao Estado.

b) Perfil centrado na dinâmica hospitalar: neste, o foco das demandas será o suporte social na intercessão das necessidades sociais e de saúde dos usuários vinculados às instituições hospitalares. Caracteriza-se pela existência de uma parceira entre a ONG e o hospital na complementaridade das "lacunas" da política de saúde e da articulação com outras políticas sociais. A atenção é voltada para a pobreza na interface com a saúde, cuja ênfase é a materialidade no acesso a equipamentos, alimentação e medicamentos, para a manutenção do tratamento da saúde (que deveriam estar sendo fornecidos enquanto direito social). Os voluntários serão compostos e mobilizados pela identificação com o hospital e alicerçados nas propostas das ONGs. Exemplos desse tipo perfil são as organizações de apoio aos hospitais públicos e de ex-funcionários.

c) Perfil centrado na prestação de serviços: neste grupo, a centralidade será a prestação de serviços na área da saúde (médica e odontológica) para pessoas oriundas de comunidade de baixa renda. A principal característica é que o trabalho é composto por profissionais voluntários, calcados em propostas de prevenção e promoção da saúde para população de baixa renda. O trabalho voluntário terá um caráter profissional, mobilizado por princípios de educação em saúde e pautados em discursos humanitários de responsabilidade profissional com a sociedade. Os exemplos desse perfil são as associações de profissionais e grupos profissionais com propostas de práticas inovadoras.

É plausível afirmar que esses diferentes perfis das ONGs expressam "vestígios" de duas heranças antagônicas e contraditórias: uma de origem dos movimentos sociais, na década de 1980, ligada às conquistas democráticas e de cidadania, e outra oriunda do projeto neoliberal, na década de 1990, de desmonte da política social do Estado, pautada na cultura do favor. 
Em nossa experiência ${ }^{3}$ podemos identificar que as ONGs no campo da saúde mesclam discursos conservadores (reestruturação da família, higiene, moralidade de condutas) e progressistas (cidadania, situação social na produção e no aprofundamento da doença). As intervenções aparecem atravessadas por antigas práticas de voluntariado, pautadas na cultura do favor, centralizadas na família em interface com a saúde, orientadas por uma gestão na lógica empresarial (eficiência e eficácia) no trato da questão social no processo de saúde-doença, mensurados por indicadores de saúde, sob um verniz do discurso da cidadania.

As ONGs no campo da saúde são uma unidade dinâmica e contraditória na intercessão do público e do privado, pois se localiza numa relação da saúde pública com um tipo de "assistência social" privada, imersa por demandas relacionadas à saúde. Em nosso ponto de vista, as ONGs no campo da saúde além de serem expressão do Estado mínimo, oriundo do sistema neoliberal, que transfere para a esfera privada os direitos sociais e sua execução, tem como consequências diretas a fragilização do estatuto de cidadão. O movimento de refilantropização está balizado na reatualização de condutas e valores do século XIX.

Conforme observamos nas reuniões da rede de profissionais das ONGs, composta em sua maioria por assistentes sociais, os conflitos mais pertinentes e persistentes são os que ocorrem cotidianamente com os voluntários ${ }^{4}$ na condução do trabalho, pois estes tentam impor a lógica do favor às intervenções sociais. Ou seja, voluntários vinculados às práticas de solidariedade muitas vezes diluem o caráter igualitário e universal dos direitos sociais, garantidos constitucionalmente.

Uma assistente social declara que estamos vivendo a "Maldição da Mary Richmond". O confronto do Serviço Social com os voluntários está na origem de nossa profissão. Vejamos o retorno dos fantasmas de Richmond, na sua fala em 1922 no livro O que é Serviço Social de caso,

Os assistentes sociais que se desgastam com a incumbência de proteger sua profissão das indignidades praticadas por pessoas inexperientes e egoístas talvez encontrem consolação no fato de que outros profissionais passaram pela mesma situação. Nos

3. A análise está ancorada nas observações sistemáticas das reuniões de assistentes sociais de dezessete ONGs no campo da saúde e na nossa experiência cotidiana. Deve-se ressaltar que a maioria dos atendimentos é realizada com as mães das crianças e adolescentes, que são oriundas de regiões pauperizadas e com experiência de abandono do companheiro, após vivência de adoecimento do filho.

4. O poder do voluntariado emana da base econômica, pois contribui para as ONGs na diminuição de pagamentos de mão de obra, sendo também fonte de captação de recursos financeiros e humanos. 
Estados Unidos, não há muito anos, podia-se comprar diploma. Em pleno século XIX muitos estados confiavam em juízes sem treino legal, enquanto o chefe dos magistrados de Rhode Island era um fuzileiro. (Rios, 1999, p. 12)

Essa situação expressa uma verdadeira combinação de determinações econômicas, políticas, culturais e sociais, misturando o passado e o presente (Behring, 2003). É verdade que a história não volta atrás, mas, ela pode incubar as piores novidades (Bensaid, apud Behring, 2003).

Esses fatos nos levam de volta ao encontro com o passado do diagnóstico social. O conceito de diagnóstico no Serviço Social esteve intimamente ligado com a trajetória histórica da profissão. A influência higienista ${ }^{5}$ na obra de Mary Richmond $^{6}$ aparece no "Caso social", que define a atuação profissional nos "aspectos diretamente relacionados com a personalidade, a saber: reestruturação da autossuficiência, problemas de saúde e higiene pessoal, bem como a complexidade da higiene mental" (1922, p. 16).

Mary Richmond buscou agregar os conceitos médicos nas abordagens sociais, consagrando o Serviço Social como uma profissão do "social", cujo trabalho aparece articulado com a dimensão "subjetiva na ênfase biológica da 'patologia social' com o 'meio social-natural'. Neste sentido, o tratamento dos sujeitos afetados pelas refrações da "questão social" era visto como individualidade sociopática, que levou à conversão dos problemas sociais em patologias sociais ${ }^{7}$ (Netto, 2005).

No estudo do Serviço Social francês, Verdès-Leroux (1986) aponta a ligação da medicina com a profissão,

[...] a autoridade da tutela médica define as referências intelectuais, o quadro da formação e os modos de operação: as pesquisas são realizadas nos moldes da pesquisas sobre higiene; as intervenções, analisadas em termos diagnósticos, seguidos de trata-

5. A concepção de ajustamento derivou do conceito biológico de adaptação de Darwin, que considerava que aquelas espécies de animais, estruturas biológicas e processos que melhor respondessem às exigências do meio ambiente e sobrevivessem a riscos e perigos eram organismos, estruturas ou processos bem adaptados ou bons. Analogamente, o comportamento humano que satisfaz de maneira adequada às exigências de seu meio é uma atividade adaptativa, e o indivíduo que enfrentou com êxito às exigências e expectativas do seu mundo físico e social é bem ajustado (Sawrey e Telford, 1971).

6. Mary Richmond admirava enormemente Adolf Meyer (higienista mental), com quem frequentemente trocava ideias (Silva, 1993). No desenvolvimento do trabalho veremos mais detalhadamente esta repercussão no Serviço Social.

7. A sociologia funcionalista está impregnada não só por "conceitos", mas também pela racionalidade médica (Luz, 2005). 
mento. Essa tutela é perceptível nas formulações, já que o emprego de um vocabulário científico permite, por meio de um deslocamento de registro, a introdução da noção de higiene social e de patologia social. [...] insiste-se nas noções de taras e de doenças mentais. Através das metáforas, impõe-se uma visão do mundo social tal como da saúde-estado precário; o corpo social está constantemente ameaçado por infecções, contaminações e epidemias. (p. 31)

Vasconcelos (2000) coloca que o Serviço Social brasileiro recebe a influência médica higienista, ${ }^{8}$ por meio da matriz franco-belga e norte-americana, sendo que a influência higienista permanece até meados da década de 1970, conforme identificado nas grades curriculares. O higienismo surge no Brasil na época da colônia, a partir da articulação entre o Estado, a religião e a medicina, a fim de exercer o controle das famílias. A corte portuguesa começou a se interessar pelas cidades brasileiras a partir da descoberta do ouro. Simultaneamente, surgia uma elite, relativamente diferenciada do reino, que se opôs à extorsão econômica de Portugal. As tentativas de controle eram realizadas de forma truculenta (enforcamento, exílio, açoite etc.), contudo, não conseguiram modificar as relações estabelecidas entre o Estado, o clero e as famílias. "A reconversão das famílias ao Estado pela higiene tornou-se uma tarefa urgente dos médicos" (Costa, 1983, p. 31).

Uma das estratégias dos médicos higienistas para intervir na família foi a manipulação da religião, por meio da apreensão do discurso da Igreja acerca da alma. A alma foi vista como sede das paixões, alvo sensível e vulnerável aos efeitos mórbidos dessas mesmas paixões. Definida como núcleo emissor desses pseudópodos morais que eram as paixões, terminava por estabelecer sinapses com as ramificações biológicas do instinto da propagação. Essa relação orgânica-moral com o corpo fez com que se criasse um afastamento progressivo do vínculo com o espírito. "O cuidado higiênico com o corpo fez do preconceito racial um elemento constitutivo da consciência de classe burguesa. [...] A consciência de classe tem, na consciência da superioridade biológico-social do corpo, um momento indispensável à sua formação" (Costa, 1983, p. 13).

8. Em nosso ponto de vista, a intervenção dos assistentes sociais foi um dos sustentáculos para medicalização da vida social. Medicalização é um processo pelo qual o modo de vida dos homens é apropriado pela medicina e que interfere na construção de conceitos, regras de higiene, normas de moral e costumes prescritos — sexuais, alimentares, de habitação — bem como de comportamentos sociais (Luz, 2004). Em nosso ponto de vista, a psiquiatria e a medicina social na Europa e nos Estados Unidos fortaleceram as bases "científicas" de legitimidade do Serviço Social na intervenção nas sequelas da questão social, expressa na concepção do diagnóstico social e do caso social sob espectro da patologia social. 
Lima (1978) aponta que o trabalho do Serviço Social estava ancorado em dois eixos: médico e jurídico, que apresentava uma concepção mesclada de filantropia, caridade ou assistência, de certo modo tecnificada. Os problemas individuais eram manipulados de forma paternalista, atendendo a certos aspectos de caráter social, como: aglomerações, promiscuidade, desnutrição, tudo aquilo que causasse ou propagasse enfermidades sociais. $\mathrm{O}$ assistente social se assemelhava a um auxiliar médico, buscava a melhor maneira de tratar as enfermidades, sempre atento ao problema dominante da defesa ou da recuperação da saúde.

À luz da formação brasileira podemos identificar que o trabalho cotidiano do assistente social é revestido por uma reatualização de velhos discursos e práticas: o voluntariado, o controle higienista das famílias e o favor, orientado por filantropia mercantilizada.

Para Iamamoto (2008), o novo é mediado pelo arcaico, que recria elementos de nossa herança colonial e patrimonialista, que atualiza marcas persistentes e, ao mesmo tempo, se transforma, no contexto de mundialização do capital sob hegemonia financeira.

As ONGs, no campo da saúde, têm como fio condutor a refilantropização e a mercantilização, tensionadas pelas conquistas democráticas ligadas à cidadania. No âmbito da intervenção do assistente social, essas tendências se expressam na "reatualização" do "arcaico", no sentido de que o campo é permeado por uma lógica pendular, da medicalização "higienista" e do favor no trato da questão social, que se encontram em disputa com o projeto ético-politico profissional e da cidadania no horizonte do cotidiano. Não podemos esquecer que o cotidiano das ONGs é mobilizado pela contradição, sendo necessário que o assistente social consiga fazer a leitura dos projetos societários em confronto, que possa construir estratégias, que viabilize a organização da população usuária na garantia de direitos.

\section{A pesquisa enquanto estratégia: relatando a experiência}

"Não está morto quem peleia" (Anônimo)

O processo de trabalho na ONG se estrutura em torno de três projetos: atendimento familiar (repasse de medicamentos, alimentos e orientações sociais do 
serviço social); moradia (melhoria habitacional, relacionada à situação de saúde) e trabalho (geração de renda e profissionalização). Os projetos estão calcados num conceito ampliado de saúde, uma vez que o processo saúde-doença abrange situações de moradia, saneamento, renda, alimentação, educação, acesso a lazer e bens.

O trabalho é centralizado na intervenção junto às famílias na órbita do direito social, pois possibilita a materialidade no acesso a equipamentos, alimentação e medicamentos garantidos constitucionalmente e que deveriam estar sendo fornecidos enquanto direito social. ${ }^{9}$ Conforme Vasconcelos (1997, p. 134),

A existência de um direito social não determina que se tenha acesso a ele como tal. $\mathrm{O}$ direito existe formalmente, mas, dependendo da forma como se usufrui dele, transforma-se num objeto de favor, doação, constrangimento, troca... O acesso a um recurso por um cidadão-sujeito social-crítico, consciente, é que transforma o direito formal em direito real.

O Serviço Social tem como base de intervenção as refrações da questão social na interface do processo-doença de crianças e adolescentes. Geralmente, cabe ao assistente social fazer a acolhida, que é uma avaliação da demanda, com objetivo de mapear as necessidades sociais e de saúde, a fim de estabelecer um plano de intervenção (o que será fornecido pela instituição, que tipo de orientações de direitos sociais serão necessários, encaminhamentos para programas internos e externos etc.). A acolhida visa identificar, por meio de entrevistas, aspectos não só da demanda explícita, ligados às questões econômicas (de acesso a medicamentos, alimentos, leites especiais), mas, principalmente, determinantes das relações sociais imbricados na dinâmica sociofamiliar, que possam potencializar o exercício da cidadania. A intervenção caminha no sentido da direção ideopolítica do fortalecimento dos dispositivos de direitos sociais garantidos na seguridade social, bem como a constituição de espaços democráticos nas ONGs que fomentem as lutas cotidianas contra-hegemônicas dos sujeitos atendidos, que subvertam a lógica do favor.

A luta por direitos inclui a apropriação de oportunidades abertas pelas conjunturas políticas, sendo necessária a mudança em identidades sociais - rompendo com a passividade de categorias administrativas (usuário, clientela, público-alvo) —,

9. O perfil dessa ONG está centrado na demanda do hospital. 
que pressupõem a compreensão das distintas faces do poder, envolvidas na relação social questionada pela ação, seja esta o protesto, a indignação ou a revolta (Ribeiro, 2004).

Por meio de nosso trabalho observamos a insastifação dos integrantes do projeto de geração de renda, ${ }^{10}$ cujas principais queixas eram: insatisfação do retorno financeiro (aliado a "sentimentos de exploração") e a dificuldade de participar do projeto, por não ter com quem deixar os filhos. ${ }^{11}$

No entanto, nossa condição de assalariado nos impunha certos condicionamentos para um diálogo direto e aberto junto à coordenação do projeto e à direção da instituição. Além disso, não poderíamos expor os usuários, que dependiam desse recurso financeiro. Em que pese tal afirmação, é preciso frisar que o profissional nesse processo não se resume a expectador ou ouvinte, mas a participante com responsabilidade de desburocratizar a prestação de serviço, de possibilitar a reflexão e de apresentar propostas viáveis para os sujeitos envolvidos (Vasconcelos, 1997).

O exercício profissional agrega um complexo de novas determinações e mediações essenciais, sendo que é uma unidade contraditória de trabalho concreto e trabalho abstrato. $\mathrm{O}$ exercício profissional especializado realiza-se por meio do trabalho assalariado alienado. Esta condição sintetiza tensões entre o direcionamento que o assistente social pretende imprimir ao seu trabalho concreto e os constrangimentos inerentes ao trabalho alienado, que se repõem na forma assalariada do fazer profissional (Iamamoto, 2008).

Para Baptista (1993), o assistente social trabalha entre dois polos: em um no qual o empregador que solicita com uma demanda específica, originada nas políticas e estratégias institucionais; em outro as pessoas que vêm buscar o recurso

10. O programa de geração de renda funciona uma vez na semana, sendo custeados o transporte, a alimentação e o material. O pagamento do trabalho é feito com base na produção individual.

11. A pesquisa apontou que família é um importante suporte no cuidado dos filhos das integrantes para que elas possam estar na programa (47\%). Outro dado que chama atenção é a situação de que os filhos das integrantes geralmente ficam sozinhos (23\%), ou com os irmãos mais velhos (18\%), somando um percentual de $41 \%$. Vale ressaltar que a maioria das entrevistadas cujos filhos ficam sós relatam que estes ficam sob os cuidados dos parentes que moram próximo. Os dados nos revelam também a falta de creches públicas e escolas em tempo integral de forma que as integrantes possam deixar seus filhos para trabalharem. Outro fato é a dificuldade de esses locais aceitarem crianças com doenças crônicas, que implicam dietas especiais, uso de medicamentos, sondas etc. 
disponibilizado e, na maior parte das vezes, não têm acesso a ele. Esta situação cria um "falso dilema", em que o profissional geralmente procurar definir "de que lado está", desqualificando a natureza contraditória em que ele opera. O dilema não está em optar por qual dos lados atender, mas superar essa contradição no sentido de reelaborar essa demanda.

A partir deste contexto, procuramos construir uma estratégia de democratização das relações sociais na direção do projeto ético-político na ONG por meio da pesquisa de avaliação participativa junto aos integrantes dos programas institucionais, que contemplasse o impacto, as demandas implícitas dos sujeitos, seus conhecimentos acerca dos direitos sociais e serviços públicos, e o que deveria melhorar na atuação do Serviço Social nos projetos. Segundo Vasconcelos, a prática é ato e movimento. O voltar-se permanente sobre a prática contribui para ação pensada, avaliada quanto aos seus objetivos, metas, resultados, dando visibilidade ao seu desenvolvimento. Acreditamos que "a avaliação permite aflorar as diversas 'verdades' sobre os propósitos e resultados do programa ou ação institucional" (Carvalho, 2007, p. 91).

A pesquisa foi organizada junto ao estágio das acadêmicas de Serviço Social sob nossa responsabilidade e coordenação. A escolha da pesquisa de avaliação participativa enquanto estratégia foi motivada por três aspectos:

- a possibilidade de sair das questões individuais do atendimento para transformá-las em uma demanda coletiva e que possibilitasse a construção de propostas interventivas em sintonia com as necessidades dos sujeitos;

- fomentar um olhar crítico e propositivo das estagiárias, partindo da análise concreta da realidade institucional e social;

- ampliar a legitimidade da intervenção do Serviço Social.

Pudemos observar que a realização da pesquisa possibilitou um canal coletivo de escuta às necessidades da população atendida, além de avaliação acerca dos programas e da própria atuação do Serviço Social. A população pôde participar na redefinição do planejamento dos projetos do Serviço Social.

As estagiárias tiveram oportunidade de realizar a pesquisa, em que puderam não apenas executar, mas elaborar, participando de todas as etapas, fortalecendo sua bagagem teórico-metodológica e instrumental técnica-operativa, alicerçadas na direção ético-política profissional. Atualmente, exige-se um profissional crítico e 
capaz de formular, recriar e avaliar propostas que apontem para a progressiva democratização das relações sociais, orientado por um compromisso ético-político pautado em competências teórico-metodológicas, na teoria crítica, na explicitação da vida social, aliado a uma capacidade técnica-operativa que possibilite a pesquisa da realidade, a fim de decifrar as situações particulares das refrações com a questão social, com a qual o assistente social defronta-se (Iamamoto, 2008).

Esta investigação proporcionou às acadêmicas fazer análise institucional não só pelo viés da instituição e da academia, mas principalmente pela ótica da população. A avaliação da situação concreta dos usuários, dos programas e do próprio Serviço Social contribuiu para o planejamento de ações de cunho participativo e democrático, que realmente pudessem alcançar os anseios da população atendida.

Concluindo, citamos Vasconcelos (1997, p. 162), para quem "teorizar sobre a democracia e sobre solidariedade não é mesmo que viver democraticamente e ser solidário".

\section{Considerações finais}

Este artigo buscou trazer apenas contribuições iniciais nesse tenso debate do trabalho do Serviço Social nas ONGs no campo da saúde. Este estudo não teve em nenhum momento a intenção de esgotar a temática, mas sim de tentar sistematizá-la e ampliá-la para proporcionar um melhor entendimento do exercício profissional nesse campo sócio-ocupacional. Conforme relatamos, acreditamos que o trabalho do assistente social nas ONGs no campo da saúde traz dilemas e desafios no horizonte da cidadania. Acreditamos que é imprescindível que o profissional avance na realidade concreta, entendendo que o real é formado por contradição e por projetos societários em disputa. Cabe a nós, profissionais, direcionarmos os projetos em disputa rumo à cidadania de direitos, em contraponto à cultura do favor. Finalizamos o artigo com um poema que expressa a síntese do fazer do Serviço Social nas ONGs na atualidade:

\footnotetext{
É urgente inventar novos atalhos acender novos archotes e descobrir novos horizontes. É urgente quebrar o silêncio, abrir fendas ao tempo
} 


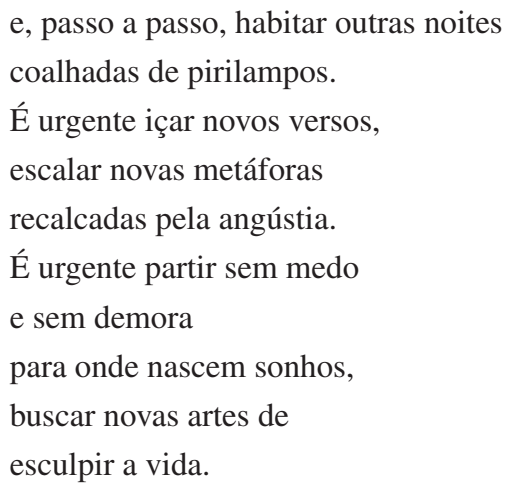

Artigo recebido em jul./2009 a Aprovado em mar./2010

\section{Referências bibliográficas}

ALVAREZ, Sonia et al. Cultura e política nos movimentos latino-americanos. Belo Horizonte: Ed. UFMG, 2000.

BAPTISTA, Myrian Veras. Questões que se colocam para investigação. São Paulo: PUC-SP. Textos para fins didáticos, ago. 1993.

BECKER, Daniel. Organizações da sociedade civil e políticas públicas em saúde. In: GARCIA, Joana; LANDIM, Leilah; DAHMER, Tatiana. Sociedades \& políticas: novos debates entre ONGs e universidade. Rio de Janeiro: Revan, 2003.

BEHRING, Elaine. Brasil em contrarreforma: desestruturação do estado e perda de direitos. São Paulo: Cortez, 2003.

CARVALHO, Maria do Carmo Brant de. Avaliação participativa: uma escolha metodológica. In: RICO, E. M. Avaliação de políticas sociais: uma questão em debate. São Paulo: Cortez, 2007.

COSTA, Jurandir Freire. Ordem médica e norma familiar. Rio de Janeiro: Graal, 1983.

DAGNIMO, Evelina. Cultura, cidadania e democracia: a transformação dos discursos e práticas na esquerda latino-americana. In: ALVAREZ, Sonia et al. (Org.). Cultura e política nos movimentos latino-americanos. Belo Horizonte: Ed. UFMG, 2000. 
FALEIROS, Vicente de P. O que é política social. São Paulo: Brasiliense, 1986.

FAGUNDES, Helenara Silveira. O voluntariado, a solidariedade e as políticas sociais. In: Revista virtual Textos \& Contextos, ano V, n. 6, dez. 2006. Disponível em: <www. pucrs.com.br>. Acesso em: mar. 2009.

GOHN, Maria da Glória. Teorias do movimentos sociais: paradigmas clássicos e contemporâneos. São Paulo: Loyola, 2000.

IAMAMOTO, Marilda V. O Serviço Social na contemporaneidade: trabalho e formação profissional. 4. ed. São Paulo: Cortez, 2001.

. Questão social no capitalismo. Temporalis, Porto Alegre, ano II, n. 3, 2001.

. Serviço Social em tempo de capital fetiche. São Paulo: Cortez, 2008.

LIMA, Alexis Boris. Contribuição à metodologia do Serviço Social. Belo Horizonte: Interlivros, 1978.

LUZ, T. Mandel. Natural, racional, social: razão médica e racionalidade moderna. São Paulo: Hucitec, 2004.

MONTAÑO, Carlos. Terceiro setor e questão social: crítica ao padrão emergente de intervenção social. São Paulo: Cortez, 2002.

NETTO, José P. Capitalismo monopolista e o Serviço Social. São Paulo: Cortez, 2005 .

RICHMOND, Mary. O que é Serviço Social de caso (material condensado). Rio de Janeiro: CBCISS, n. 85, 1999.

RIBEIRO, Ana Clara Torres. Leituras de movimentos: conjuntura, ação e poder. Temporalis, Porto Alegre, ano II, n. 4, 2004.

SAWREY, James M.; TELFORD, Charles W. Psicologia do ajustamento. São Paulo: Cultrix, 1971.

SILVA, Creusa da Costa. A responsabilidade social como uma fonte de captação de recursos financeiros. Rio de Janeiro: Universidade Veiga de Almeida (UVA), 2009.

SILVA, Maria Luiza Campos. Da higiene à psicanálise. 1993. Tese (Mestrado) — Pontifícia Universidade Católica do Rio de Janeiro (PUC-RJ), Rio de Janeiro.

VASCONCELOS, Ana M. et al. Serviço Social e práticas democráticas na saúde. In: BRAVO, Maria Inês Souza et al. (Org.). Serviço Social e saúde. São Paulo: Cortez, 2008. p. 242-272.

Serviço Social e prática reflexiva. Em Pauta, Faculdade de Serviço Social, UERJ, n. 10, 1997. 
VASCONCELOS, Eduardo M. et al. Saúde mental e Serviço Social: o desafio da subjetividade e da interdisciplinaridade. São Paulo: Cortez, 2000.

VERDÉS-LEROUX, Jeannine. Trabalhador social: prática, hábitos, ethos, formas de intervenção. São Paulo: Cortez, 1986.

YAZBEK, Maria Carmelita. Pobreza e exclusão social: expressões da questão social no Brasil. Temporalis, Porto alegre, ano II, n. 3, 2001. 